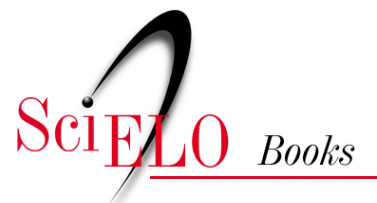

\title{
8. A Abrasco e a Pós-Graduação Stricto Sensu em Saúde Coletiva
}

\author{
Rita Barradas Barata
}

\section{SciELO Books / SciELO Livros / SciELO Libros}

BARATA, R.B. A Abrasco e a Pós-Graduação Stricto Sensu em Saúde Coletiva. In: LIMA, N.T., SANTANA, J.P., and PAIVA, C.H.A., orgs. Saúde coletiva: a Abrasco em 35 anos de história [online]. Rio de Janeiro: editora FIOCRUZ, 2015, pp. 169-198. ISBN: 978-85-7541-590-0. Available from: doi: $10.7476 / 9788575415900.0010$. Also available in ePUB from: http://books.scielo.org/id/q4gzb/epub/lima-9788575415900.epub.

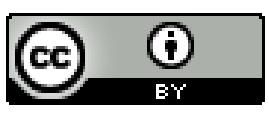

All the contents of this work, except where otherwise noted, is licensed under a Creative Commons Attribution $\underline{4.0 \text { International license. }}$

Todo o conteúdo deste trabalho, exceto quando houver ressalva, é publicado sob a licença Creative Commons Atribição 4.0. 


\section{A Abrasco e a Pós-Graduação Stricto Sensu em Saúde Coletiva}

Rita Barradas Barata

\section{Período Anterior À Criação da Abrasco: 1970-1979}

No Brasil, os primeiros programas de pós-graduação surgiram na década de 1920, de maneira isolada e antes que houvesse qualquer regulação. Nesse período, no país, a pesquisa ainda era incipiente eestava concentrada nos institutos de pesquisa, praticamente ausente das faculdades. Esses cursos surgiram como parte do movimento em prol da articulação ensinopesquisa, segundo o modelo que vinha sendo adotado nos Estados Unidos desde o século XIX, em algumas das melhores universidades (Nunes, Ferreto \& Barros, 2010).

Nunes, Ferreto e Barros (2010) informam que o termo pós-graduação foi utilizado pela primeira vez na legislação educacional brasileira na década de 1940, no Estatuto da Universidade do Brasil. A criação da Capes, inicialmente Campanha de Aperfeiçoamento do Pessoal do Ensino Superior - e hoje Coordenação de Aperfeiçoamento de Pessoal de Nível Superior-, e, em 1951, do Conselho Nacional de Pesquisas - atual CNPq, que teve seu nome modificado em 1974-foram iniciativas importantes de estímulo à pesquisa eà qualificação da formação dos docentes para as universidades. Na década de 1960, a pós-graduação brasileira passou por reformulação sob a influência de docentes e pesquisadores que fizeram doutorado no exteriore, ao retornarem ao país, propuseram-se a impulsionar a pesquisa nas universidades (Nunes, Ferreto \& Barros, 2010).

O ensino da pós-graduação stricto sensu no campo da saúde pública teve início no país na década de 1970 (Quadro 1). Até então, a formação em saúde pública ocorria apenas nos cursos de especialização, ministrados pela Faculdade de Saúde Pública da Universidade de São Paulo ou pela Escola Nacional de Saúde Pública - hoje chamada de Escola Nacional 
de Saúde Pública Sergio Arouca (Ensp) - da Fundação Oswaldo Cruz (Fiocruz), ou ainda nas residências médicas em medicina preventiva ou social mantidas por alguns departamentos de escolas médicas (Barata, 1997).

Quadro 1 - Programas de pós-graduação iniciados antes da criação da Abrasco. Brasil - 1970-1979

\begin{tabular}{|l|c|c|c|}
\hline \multicolumn{1}{|c|}{$\begin{array}{c}\text { Instituição de } \\
\text { ensino superior }\end{array}$} & $\begin{array}{c}\text { Programa de } \\
\text { pós-graduação }\end{array}$ & $\begin{array}{c}\text { Ano início } \\
\text { mestrado }\end{array}$ & $\begin{array}{c}\text { Ano início } \\
\text { doutorado }\end{array}$ \\
\hline USP (FSP) & Saúde Pública & 1970 & 1970 \\
\hline USP/RP & $\begin{array}{c}\text { Medicina Preventiva (anteriormente) } \\
\text { Saúde na Comunidade (atualmente) }\end{array}$ & 1971 & $\begin{array}{c}1971 \text { (cessou } \\
\text { em 2001) } \\
\text { reinício 2011 }\end{array}$ \\
\hline USP (FM) & Medicina Preventiva & 1973 & 1973 \\
\hline Ufba & Saúde Comunitária & 1974 & $1989^{*}$ \\
\hline IMS/Uerj & Saúde Coletiva (atualmente) & 1974 & $1990^{*}$ \\
\hline Ensp/Fiocruz & Saúde Pública & 1977 & $1980^{*}$ \\
\hline
\end{tabular}

*Cursos iniciados após a criação da Abrasco.

O primeiro curso de mestrado e doutorado em saúde pública criado no país teve início em 1970 na Faculdade de Saúde Pública da Universidade de São Paulo (USP), na capital paulista, somando-se assim aos cursos de especialização em saúde pública oferecidos pela instituição desde a década de 1920 (Barata \& Santos, 2013; Nunes, 2005).

Em 1971 foram criados o mestrado e o doutorado em medicina preventiva pela Faculdade de Medicina de Ribeirão Preto, unidade da USP campus de Ribeirão Preto. Em 1973, começaram a funcionar o mestradoe o doutorado em medicina preventiva da Faculdade de Medicina da Universidade de São Paulo na capital (Barata \& Santos, 2013; Nunes, 2005). Esses três cursos de doutorado seriam os responsáveis pela formação dos primeiros doutores em saúde pública no país. Até então a formação era concluída em universidades estrangeiras, notadamente nos cursos da Universidade Johns Hopkins, Columbia ou Harvard, todas nos Estados Unidos.

Ainda na década de 1970, foram criados os mestrados em saúde comunitária da Faculdade de Medicina da Universidade Federal da Bahia e o mestrado em medicina social do Instituto de Medicina Social da Universidade do Estado do Rio de Janeiro, em 1974. Finalmente, em 1977, foi criado o mestrado em saúde pública da Ensp.

Esse período foi marcado por um esforço de construção teórica do campo da saúde coletiva, de inspiração marxista e estruturalista, fortemente influenciado pelas ciências sociais aplicadas à saúde, principalmente a sociologia e a ciência política. O resultado desse esforço 
foi o afastamento progressivo em relação aos conteúdos e abordagens tradicionais da saúde pública e a adoção de posturas críticas que buscavam compreender o processo de produção social do adoecer, além de aspectos relativos à prática médica eà organização de sistemas de saúde (Nunes, 1985). Ganharam espaço também nesses cursos as discussões metodológicas estimuladas pela sistematização do método epidemiológico realizada por MacMahon e Puig (1970) e pelo trabalho de Susser (1973) sobre o pensamento causal (Barata, 1997).

Assim, até a criação da Associação Brasileira de Pós-Graduação em Saúde Coletiva (Abrasco), no fim da década de 1970, havia apenas seis cursos de mestrado no país, três no estado de São Paulo, dois na cidade do Rio de Janeiro e um em Salvador. Os três cursos de doutorado eram oferecidos pela USP, dois deles na cidade de São Paulo e um em Ribeirão Preto.

A Capes, embora criada em 1951, teve a institucionalização de seu papel de condutora da política de formação pós-graduada estabelecida apenas em 1974; portanto, no mesmo período em que os primeiros cursos no campo da saúde coletiva foram criados. Em 1977 começaram a ser criadas as comissões de assessores por área para realizar a avaliação e o acompanhamento dos cursos, e os presidentes das comissões passaram a constituir o Conselho Técnico Científico (CTC) (Ferreira \& Moreira, 2002; Capes, 2011). No início não havia uma área de saúde pública para a avaliação dos cursos, e eles eram avaliados pela área de medicina. Entretanto, até o início dos anos 1980, os conceitos dos programas não eram divulgados publicamente, eram de conhecimento exclusivo das instituições avaliadas.

Segundo Nunes, Ferreto e Barros (2010), possibilidade de organizar uma área de saúde coletiva foi discutida inicialmente no $1^{\circ}$ Encontro Nacional de Pós-Graduação em Saúde Coletiva, realizado em Salvador, e posteriormente na Reunião Sub-Regional de Saúde Pública da Associação Latino-Americana de Escolas de Saúde Pública (Alaesp) em Ribeirão Preto, ambas em 1978. A ideia de formar uma entidade que pudesse congregar todos os programas de formação em saúde coletiva nas mais diferentes modalidades só se concretizou com a criação da Abrasco, em setembro de 1979.

\section{Período de Constituição da Abrasco: 1980-1989}

A Abrasco, desde sua criação, passou a congregar professores das residências médicas, dos cursos de especialização, dos programas de pós-graduação stricto sensu, e a apoiar o desenvolvimento desses programas, além de realizar uma série de reuniões e atividades acadêmicas e científicas. A atuação se concretizava por meio de comissões, grupos temáticos (GTs), congressos, seminários e publicações congregando docentes e pesquisadores, técnicos e profissionais da saúde, gestores e formuladores da política de saúde do país (Minayo, 2010).

Durante a década de 1980, foram realizados vários seminários e encontros entre docentes dos programas de ensino, lato sensu e stricto sensu, para analisar as características dos cursos e propor formas de fortalecer o desenvolvimento do campo. Foram realizadas as 
reuniões nacionais de ensino da epidemiologia, ensino das ciências sociais em saúde ensino de planejamento e gestão em saúde. Nessas reuniões, cujos relatórios estão disponíveis em diferentes números da publicação Ensino da Saúde Pública, Medicina Preventiva e Social no Brasil, editada pela Abrasco nos anos 1983, 1986 e 1989, a maior parte dos participantes era constituída por preceptores dos programas de residência médica. As discussões estavam voltadas para essa modalidade de formação profissional, uma vezque o número de programas de pós-graduação stricto sensu era ainda reduzido.

Ao longo da década, acompanhando o processo de redemocratização do país, a Abrasco envolveu-se cada vez mais com a ação política, visando a concretizar a Reforma Sanitária brasileira, e as questões relativas ao ensino foram cedendo lugar às questões relacionadas com a formulação do Sistema Único de Saúde (SUS). A associação teve papel protagonista na organização e realização da $8^{a}$ Conferência Nacional de Saúde e na atuação da comissão da Reforma Sanitária durante os trabalhos da Assembleia Nacional Constituinte, que resultaram na elaboração e aprovação do capítulo sobre a saúde. Do mesmo modo, a Abrasco participou ativamente no processo de elaboração e aprovação da Lei Orgânica do Sistema Único de Saúde e da regulamentação da participação social no sistema de saúde (Goldbaum \& Barata, 2006).

No fim dos anos 1980, havia apenas cinco programas em saúde coletiva que ofereciam cursos de mestrado e doutorado - três em São Paulo, um no Rio de Janeiro e um em Salvador -e três mestrados - dois no Rio de Janeiro, um dedicado à saúde coletiva e outro ao tema de saúde da criança e da mulher, e um em São Paulo dedicado exclusivamente à epidemiologia (Quadros 1 e 2).

Quadro 2 - Programas de pós-graduação iniciados entre 1980 e 1989 - Brasil

\begin{tabular}{|l|c|c|c|}
\hline \multicolumn{1}{|c|}{$\begin{array}{c}\text { Instituição de } \\
\text { ensino superior }\end{array}$} & $\begin{array}{c}\text { Programa de } \\
\text { pós-graduação }\end{array}$ & $\begin{array}{c}\text { Ano início } \\
\text { mestrado }\end{array}$ & $\begin{array}{c}\text { Ano início } \\
\text { doutorado }\end{array}$ \\
\hline IFF/Fiocruz & Saúde da Criança e da Mulher & 1988 & 1996 \\
\hline Unifesp & Epidemiologia & $\begin{array}{c}1989 \\
\text { encerrado em 2005 }\end{array}$ & \\
\hline
\end{tabular}

Na Capes, a atuação das comissões de avaliação prosseguia organizada por áreas do conhecimento, e os programas do campo da saúde coletiva eram analisados na área de ciências médicas. A partir de 1982, as avaliações passaram a ser divulgadas publicamente. As dificuldades e as reações negativas à divulgação dos resultados dão ideia do estágio ainda incipiente dos mecanismos de avaliação nesse momento. Por incentivo da Capes, as universidades começam a instituir as Pró-Reitorias de Pós-Graduação e Pesquisa para facilitar a interlocução com o órgão (Ferreira \& Moreira, 2002).

No campo da formação acadêmica em saúde coletiva, podemos assinalar os anos 1980 como um momento de crescimento e de abertura para numerosas influências de ordem 
teórica e metodológica, mas também de ordem política e institucional. A primeira metade da década foi marcada pela influência muito forte da medicina social latino-americana e da epidemiologia social. As contribuições originais que a incorporação das ciências sociais, principalmente a sociologia de cunho marxista, trouxe para o campo da saúde coletiva apresentaram vários desdobramentos, fortalecendo a perspectiva interdisciplinare acentuando a colaboração entre cientistas sociais e epidemiologistas nos estudos do processo saúde-doença - assim como a colaboração entre cientistas sociais e gestores no âmbito da formulação do direito à saúde e no desenho de um sistema nacional de saúde baseado nos princípios da universalidade, integralidade e equidade.

As pesquisas desenvolvidas nesse período revelavam as virtudes e dificuldades desse empreendimento interdisciplinar que pretendia refundir conhecimentos ultrapassando o nível fenomênico dos processos, desvelando as desigualdades geradas e mantidas por uma estrutura social iníqua - desigualdades essas que tanto se manifestavam no viver, adoecer e morrer dos grupos humanos quanto nas diferenças deacesso e utilização de serviços de saúde.

Na segunda metade da década de 1980 se assistiu a um movimento até certo ponto oposto ao anteriormente descrito. $O$ enorme desenvolvimento das técnicas estatísticas de análise de dados e a disseminação do uso de computadores produziram uma guinada das pesquisas na área para uma formulação mais técnica, com empobrecimento das concepções teóricas. Nesse processo de afastamento entre as disciplinas que constituem o campo da saúde coletiva, também houve a influência da experiência de docentes que foram fazer sua formação pós-graduada em nível de doutorado no exterior. Os cursos para obtenção do PhD eram em sua maioria disciplinares, oferecendo formações acadêmicas específicas em epidemiologia, bioestatística, pesquisa em serviços de saúde ou ciências comportamentais. Os doutorados em saúde pública com caráter profissional foram menos procurados pelos docentes das universidades brasileiras, que saíram em busca de formação acadêmica.

Os programas na área de saúde coletiva apresentaram maior crescimento após a criação da área de avaliação em saúde coletiva pela Capes e a sua inclusão na árvore de conhecimentos do Conselho Nacional de Desenvolvimento Científico e Tecnológico (CNPq), conforme será comentado na próxima seção.

\section{A Criação da Área de Avaliação em Saúde Coletiva: 1990-1999}

No início da década de 1990, durante o primeiro governo eleito após a ditadura militar, a Capes foi extinta logo após a posse presidencial. A reação da comunidade acadêmica foi tão intensa que em menos de um mês a medida foi revertida e a professora Eunice Durham assumiu a presidência da agência. No ano seguinte, a agência foi transformada em Fundação Capes, sob a presidência de Sandoval Carneiro Junior (Ferreira \& Moreira, 2002). Nesse momento, ocorreu uma primeira mudança no sistema de avaliação, com a substituição dos 
conceitos A, B, C, D e E pelas notas de um a cinco e a introdução das notas seis e sete para destacar os programas com maior grau de internacionalização. Além disso, a avaliação até então eminentemente qualitativa começa a incluir alguns indicadores quantitativos.

Em 1992, após o impeachment do presidente Collor e a posse do vice Itamar Franco, a Fundação Capes teria em sua presidência um membro da Abrasco, a professora Maria Andrea Loyola, do Programa de Pós-Graduação do Instituto de Medicina Social da Universidade do Estado do Rio de Janeiro (IMS/Uerj).

Maria Andrea Loyola formou-se em ciências sociais pela Faculdade de Filosofia e Letras de Juiz de Fora (MG), fez o mestrado em antropologia social no Museu Nacional da Universidade Federal do Rio de Janeiro (UFRJ) e o doutorado em sociologia na Universidade de Paris. De volta ao Brasil, durante a ditadura militar, integrou a equipe do Centro Brasileiro de Análise e Planejamento (Cebrap) e o quadro docente da Pontifícia Universidade Católica de São Paulo até meados da década de 1980. Em 1988, assumiu a direção do Instituto de Medicina Social da Uerj. Durante toda a década de 1980, sua produção intelectual foi realizada no campo das ciências sociais em saúde. Durante os dois anos em que presidiu a Capes, trabalhou arduamente para recompor o orçamento da agência, instituiu as bases para a informatização dos processos de julgamento e deu maior consistência ao processo avaliativo, o que resultou em aumento do reconhecimento do trabalho da agência no interior do próprio Ministério da Educação.

Suagestãoà frenteda Capesfoifundamental para o desenvolvimento da pós-graduação stricto sensu no campo, uma vezque a constituição da saúde coletiva comoárea independente de avaliação possibilitou que os critérios de avaliação dos cursos fossem mais bem ajustados às características dessecampo científico-oquenãoocorria quando os programas eramavaliados segundo os critérios das ciências médicas. Durante a década de 1990, foram criados 14 cursos de mestrado e cinco cursos de doutorado, fazendo com que em dez anos dobrasse o número de cursos em relação aos que haviam sido criados nos vinte anos anteriores (Quadro 3).

Em termos da organização interna da Abrasco, o crescimento dos programas de pósgraduaçãostricto sensu ocorreu simultaneamenteao decréscimo dos programas deresidência médica ou multiprofissionais. Progressivamente, as atividades associativas foram migrando da formação pós-graduada lato sensu para a pós-graduação stricto sensu, e a questão da política científica ganhou espaço ao lado do envolvimento tradicional com a política de saúde.

A primeira representante deárea na Capes foi a professora Maria Cecília de Souza Minayo, graduada em sociologia pela UFRJ e em ciências sociais pela City University of New York. Fez mestrado em antropologia social na UFRJ e doutorado em saúde pública na Ensp, onde passou a fazer parte do corpo docente do programa de pós-graduação. Sua produção intelectual sempre esteve voltada para o campo da saúde coletiva, e sua atuação na gerência de ensino da Enspa aproximou da Abrasco desde o início de sua atividade docente. No fim de seu período como representante de área, assumiu a presidência da Abrasco para o período 1995-1997. 
Quadro 3 - Programas de pós-graduação iniciados entre 1990 e 1999 - Brasil

\begin{tabular}{|l|l|c|c|}
\hline $\begin{array}{l}\text { Instituição de ensino } \\
\text { superior }\end{array}$ & $\begin{array}{c}\text { Programa de } \\
\text { pós-graduação }\end{array}$ & $\begin{array}{c}\text { Ano início } \\
\text { mestrado }\end{array}$ & $\begin{array}{c}\text { Ano início } \\
\text { doutorado }\end{array}$ \\
\hline UEL & Saúde Coletiva & 1990 & 2009 \\
\hline Unicamp & Saúde Coletiva & 1991 & 1991 \\
\hline Ufpel & Epidemiologia & 1991 & 1998 \\
\hline UFMS & Saúde Coletiva & 1993 & \\
\hline UFC & Saúde Pública & 1994 & 2002 \\
\hline UFMG & Saúde Pública & 1994 & 1999 \\
\hline UECE & Saúde Pública & 1994 & 2009 \\
\hline CPqAM/Fiocruz & Saúde Pública & 1996 & \\
\hline UFSC & Saúde Coletiva & 1996 & 2009 \\
\hline Ulbra & Saúde Coletiva & 1997 & \\
\hline UFRJ & Saúde Coletiva & 1997 & 2008 \\
\hline UFPE & Saúde Coletiva & 1998 & 2012 \\
\hline Unesp & & 1999 & \\
\hline UFRGS & Saúde Coletiva & 1999 & \\
\hline Ufes & Epidemiologia & descredenciado 2007 & \\
\hline
\end{tabular}

O momento em que Cecília Minayo assume a presidência da Abrasco corresponde a uma nova inflexão no trabalho da associação. Com a implementação do SUS, mais efetivamente em 1993, surge a necessidade de se retomar de maneira decisiva a produção de conhecimentos no campo para apoiar esse processo. É nesse contexto em que a porção mais acadêmica da associação, envolvida na formação de pesquisadores e na produção científica aplicável ao campo da saúde coletiva, ganha relevância. Vencidas as primeiras batalhas na arena política, a necessidade de demonstrar competência e capacidade técnica impõe à associação um novo rumo: o fortalecimento da pós-graduação e da produção acadêmica.

Ademanda pelofortalecimento da pós-graduação respondia a duasordens dequestões: de um lado, ajá mencionada necessidade de produzir novos conhecimentos queembasassem a implementação doSUS; de outro, o questionamento, mais ou menos velado, sobre o caráter científico do campo. Toda vez que se solicitava apoio aos órgãos de fomento para a realização das atividades da associação e nos embates por recursos para o fomento à pesquisa ou bolsas, aparecia o questionamento sobre o caráter científico e a natureza predominantemente política do campo da saúde coletiva. Exemplo desse tipo de dificuldade ocorreu logo no 
início do mandato, quando o CNPq tentou impor como coordenador do comitê de área um pesquisador de outra área do conhecimento. A mobilização da comunidade logrou impedir essa medida, porém não conseguiu garantir a indicação do nome que havia recebido o apoio da comunidade (Goldbaum \& Barata, 2006).

Diante dessa conjuntura, a estratégia adotada pela nova diretoria privilegiou a inserção da Abrasco na comunidade científica brasileira, seja por meio da participação na assembleia das sociedades científicas da Sociedade Brasileira para o Progresso da Ciência (SBPC), seja pela atuação no âmbito dos órgãos de fomento, como o CNPq, a Capes e a Financiadora de Estudos e Projetos Inovação e Pesquisa (Finep). Nesse sentido, foi muito

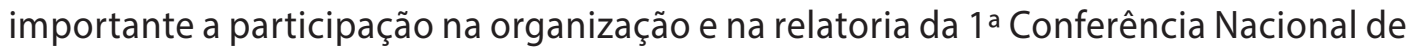
Ciência e Tecnologia em Saúde.

Baseada em sua experiência na representação de área na Capes, Cecília Minayo decidiu promover uma avaliação independente dos programas de pós-graduação, convidando dois pesquisadores estrangeiros para participar: Sherman James, da Universidade de Michigan, e Claudine Herzlich, do Institut National de la Santé et la Recherche Medicale (Inserm), da França. Esse estudo foi feito em 1995 e 1996, abrangendo os seguintes aspectos: organização dos programas, conteúdo, perfil da demanda, perfil dos egressos, produção científica e difusão científica, e foi financiado pelo CNPq e pela Capes (Minayo, 1997).

A pesquisa avaliativa permitiu destacar as peculiaridades da área que a diferenciavam de outras áreas do conhecimento, tais como ausência de formação graduada em saúde coletiva, origem multiprofissional de sua clientela, articulação intrínseca entre conhecimentos e práticas no âmbito das políticas de saúde. Também permitiu demonstrar que não havia motivos para que o campo não fosse avaliado com os critérios estabelecidos pela Capes para qualquer uma das áreas de avaliação (Minayo, 2006).

As principais conclusões dessa pesquisa avaliativa demonstraram a grande heterogeneidade no que concerne à qualidade dos programas, evidenciando diversos graus de amadurecimento e condições de infraestrutura bastante variáveis. Outra constatação foi a excessiva rigidez do sistema, com falta de clareza de objetivos para as diferentes modalidades de formação, resultando em demora excessiva na finalização dos cursos e inadequação entre oferta e demanda, uma vez que a oferta era de corte acadêmico e a demanda era predominantemente profissional. Quanto à produção científica, observaram-se forte tendência ao crescimento e indicadores compatíveis com os da área da saúde como um todo. Finalmente, um ponto importante dizia respeito às assimetrias regionais, que, embora menos pronunciadas do que no restante da área da saúde, também estavam presentes na saúde coletiva (Minayo, 1997).

Como uma das estratégias para buscar maior homogeneidade entre os programas, foi instituído pela Abrasco o Fórum de Coordenadores dos Programas de Pós-Graduação em Saúde Coletiva, visando a fortalecer o desenvolvimento dos programas e articular o 
trabalho da associação ao do representante de área na Capes, estabelecendo assim um canal permanente de comunicação entre eles.

Outra iniciativa importante tomada durante a gestão de Cecília Minayo foi a criação do primeiro periódico científico da Abrasco, a revista Ciência \& Saúde Coletiva. Desde o início de sua história, a Abrasco conferiu importância à questão editorial, buscando suprir os programas com textos de referência. Entretanto, essas publicações reunindo textos de relatórios ou contribuições teóricas de membros da instituição não eram adequadas à divulgação dos resultados de pesquisas produzidas nos programas de mestrado e doutorado. A criação da revista da Abrasco, em 1996, ampliou o espaço de divulgação de conhecimentos científicos produzidos no campo, somando-se aos Cadernos de Saúde Pública, editados pela Ensp desde 1985, eà Revista de Saúde Pública, editada pela Faculdade de Saúde Pública da USP desde 1967.

O professor Maurício Barreto, formado pela Faculdade de Medicina da Universidade Federal da Bahia (Ufba), com mestrado em saúde comunitária na própria universidade e doutorado em epidemiologia pela Universidade de Londres, assumiu a representação da área no período de 1995 a 1999. Maurício tinha sido coordenador da Comissão de Epidemiologia da Abrasco e presidiu o terceiro congresso realizado em Salvador, em 1995, mantendo estreitos vínculos com a associação.

Durante os dois mandatos de Maurício Barreto, foram criados oito mestrados e quatro doutorados, representando um acréscimo de $80 \%$ nos cursos de mestrado e $60 \%$ nos cursos de doutorado existentes em 1994 (Quadro 3). Assim, no fim da década de 1990, os programasem saúde coletiva estavam presentes em todos os estados das regiões Sule Sudeste e em três estados do Nordeste: Bahia, Pernambuco e Ceará. O crescimento dos programas após a criação da área de avaliação foi bastante acentuado. Durante 22 anos, haviam sido criados dez cursos de mestrados e sete doutorados - portanto, em média 0,8 curso por ano. Nos sete anos após a instituição da área de avaliação, foram iniciados outros 11 mestrados e quatro doutorados, em média dois cursos novos por ano. Desse modo, em 1999 a área contava com vinte programas, dos quais 11 incluíam mestrado e doutorado e nove eram exclusivamente demestrado. Havia dois programas exclusivamente dedicados à formaçãoem epidemiologia, um programa temático dedicado à saúde da criança e da mulher; os demais abarcavam o campo como um todo, ainda que com distintas denominações, tais como saúde coletiva, saúde pública, saúde comunitária e medicina preventiva.

De 1995 a 2002, a presidência da Capes foi exercida pelo professor Abílio Baeta Neves. Durante sua gestão, alguns aspectos mereceram maior atenção, repercutindo sobre todas as áreas de avaliação. Entre as preocupações centrais estavam a internacionalização da produção científica brasileira e a ampliação de acordos internacionais de cooperação. Outro destaque dessa gestão foi a criação de mestrados profissionais.

O primeiro mestrado profissional foi criado em 1974, pela Fundação Getulio Vargas de São Paulo, e era da área de administração empresarial, antes mesmo que essa modalidade 
estivesse regulamentada no país. Em 1992 foi instituído o segundo mestrado profissional, na área de economia, pela Universidade Candido Mendes, e em 1994, o mestrado profissional em administração, pela Universidade Estácio de Sá. Em 1995, foi elaborada uma portaria regulamentando a modalidade do mestrado profissional, que, entretanto, não surtiu grande efeito, pois apenas dois novos cursos foram criados nessa modalidade em 1997, ambos na grande área das engenharias.

Em 1998 nova portaria foi editada, mas as resistências a essa modalidade seguiam muito fortes na maioria das universidades que compunham o sistema nacional de pós-graduação. Em 1998 e 1999 foram criados 22 cursos de mestrado profissional, abrangendo as áreas de administração, economia, interdisciplinar, engenharias, física e odontologia - esta a primeira área da saúde a acolher essa modalidade. O Fórum de Coordenadores dos PPG em Saúde Coletiva iniciou o debate sobre essa nova modalidade sem, entretanto, atingir um consenso sobre as características que deveria ter e a forma como se diferenciaria das residências já existentes, por um lado, e dos mestrados acadêmicos, por outro.

Em 1998, a Capes propôs uma mudança substancial no processo de avaliação dos cursos, revendo uma série de indicadores que haviam perdido sentido ao longo do tempotal como o número de doutores no corpo docente dos programas e a composição das bancas, entre outros. A ficha de avaliação, padronizada nesse momento, passou a contar com sete quesitos, embora o número de itens de avaliação em cada quesito fosse bastante variável de acordo com a área de avaliação. Os quesitos avaliados no período 1998-2003 eram: a proposta do programa, o corpo docente, as atividades de pesquisa (projetos), as atividades de formação, o corpo discente, as teses e dissertações e a produção intelectual.

A preocupação com a qualidade se refletiu na proposição do Qualis-periódicos como ferramenta de avaliação da produção bibliográfica, que deveria distinguir a parcela internacionalizada dela. Finalmente, ficou instituído o papel do CTC na equalização dos critérios das diferentes áreas de conhecimento. A partir da avaliação trienal de 2001, as notas atribuídas pelos comitês teriam que ser chanceladas pelo CTC como forma de induzir a discussão dos critérios adotados em cada área, buscando equalizar os resultados.

No âmbito da saúde coletiva, esses mesmos debates foram reproduzidos no Fórum de Coordenadores de Programas, havendo intensa discussão acerca do mestrado profissional e do Qualis-periódicos. A proposta do Qualis era classificar os periódicos, nos quais a produção dos programas vinha sendo divulgada, em três categorias, de acordo com a circulação local, nacional ou internacional, e dentro de cada categoria em três estratos ( $A, B$ ou $C$ ), de acordo com critérios de relevância estabelecidos pelas áreas. Inicialmente, na saúde coletiva a proposta elaborada em conjunto pela diretoria da Abrasco e pela representação de área propôsquefossemconsideradosperiódicosAaquelesespecíficosdocampo;Baqueles demaior interface científica com o campo; e C aqueles sem essas interfaces. Seriam classificados como decirculação internacional os periódicos com indexação em bases de dados; nacionais aqueles 
editados por associações ou instituições nacionais; e locais aqueles restritos a determinados estados ou instituições sem alcance nacional.

A discussão desses critérios com os coordenadores de programas provocou vários ajustes por meio da análise de cada título, prevalecendo na classificação final o consenso estabelecido coletivamente em torno da percepção dos coordenadores sobrea sua relevância para a área. Além dos critérios no interior da área e entre as áreas da grande área da saúde, outro aspecto muito polêmico, que gerava debate, era a exclusão da produção divulgada em veículos, como livros e coletâneas, que passou a ser fonte de grande tensão entre os docentes no interior de cada programa.

Nesse momento de mudança do papel do CTC, a área foi até certo ponto privilegiada, pois pela primeira vez tinha seu representante, Maurício Barreto, como um dos membros do conselho. Assim, pelo menos era possível apresentar os critérios e discuti-los com os representantes de outras áreas de conhecimento sem precisar se valer de intermediários.

A despeito de todo o esforço para melhor qualificar a produção bibliográfica dos programas, nessemomentoa avaliação colocou maiorênfaseem um dos problemas crônicos da pós-graduação brasileira, que era o tempo muito longo de titulação e a grande taxa de evasão de alunos, principalmente no mestrado, em que muitos concluíam os créditos em disciplinas, mas não apresentavam o trabalho final. Assim, o tempo médio de titulação e o fluxo de alunos passaram a se constituir nos principais itens da avaliação, havendo forte correlação entre a nota obtida por um programa e seu desempenhonesses dois aspectos. Notriênio 1998-2000, a quase totalidade dos cursos de mestrado na área apresentava tempo mediano de titulação acima dos 28 meses, não sendo incomum a observação de 46 ou mais meses. Os cursos de doutorado, em sua maioria, apresentavam tempo mediano de titulação acima de 52 meses, ocorrendo valores entre 64 e 68 meses com alguma frequência. Em alguns programas, inclusive o tempo mediano de titulação no mestrado era maior do que o tempo mediano no doutorado.

Progressivamente, osistema deavaliaçãofoi induzindo a redução dotempo deformação no mestrado para 24 a 28 meses, e no doutorado para 48 a 52 meses. Desse modo, a evasão tornou-se residual. A partir de 2001, é mais frequente entre os cursos da área que o tempo mediano para titulaçãoesteja dentro dorecomendado.Assim, no períodoseguinte, foi possível tirar a ênfase do fluxo de alunos e colocar sobre a produção científica. Embora o fluxo de alunos fosse um dos fatores relacionados à eficiência dos programas na formação de novos pesquisadores, ele atribuía muito peso a um aspecto operacional queera o tempo de titulação, sem levar em conta o número de alunos titulados e a relação entre orientadores e alunos.

Colocar o foco na produção científica significava observar atentamente o produto dotrabalho dos programas representado pelos artigos produzidos pelos docentes, como uma medida indireta de sua capacidade para formar novos pesquisadores. Entretanto, nesse primeiro momento não houve preocupação na maioria das áreas de avaliação em vincular essa produção com aquela feita em coautoria com os alunos. 


\section{Ênfase na Produção Científica: a PRIMEIRA déCADA do séCUlo XXI}

Algumas preocupações já expressas no período anterior semantêm como orientadoras do desenvolvimento da pós-graduação brasileira, dentreelas destacando-seas iniciativas para reduzir as heterogeneidades no processo de avaliação entre as áreas e a preocupação com o aumento da produção científica dos programas. Parte da produção dos docentes e alunos não era publicada em artigos científicos em revistas indexadas, não conferindo visibilidade aos produtos da pós-graduação.

A principal iniciativa da Capes, ainda sob a presidência de Abílio Baeta Neves, para incentivar a produção científica de qualidade nos programas foi a criação do Portal de Periódicos da Capes, lançado em novembro de 2000, com cerca de 1.400 títulos, disponibilizados aos alunos e docentes dos programas de 72 instituições no país. Essa iniciativa permitiu a docentes e alunos de programas localizados fora dos grandes centros o acesso à literatura científica de qualidade. $O$ aumento dos preços das assinaturas de periódicos científicos, que passaram a ser editados por um número reduzido de casas editoriais em um processo acelerado de profissionalização, tornava cada vez mais difícil para as universidades brasileiras manter um acervo atualizado e abrangente. Nesse sentido, a criação do portal de periódicos representou uma solução extremamente inovadora e com alto potencial de impacto sobre a produção científica de qualidade.

O professor Moisés Goldbaum, formado em medicina pela USP, com mestrado e doutorado em medicina preventiva obtidos na mesma instituição, assumiu a representação da área de saúde coletiva para os mandatos de 1999 a 2004, tendo como sua adjunta a professora Madel Luz, do Instituto de Medicina Social da Uerj. Ambos eram membros atuantes da Abrasco, tendo ocupado cargos em sua diretoria e em suas comissões. Moisés Goldbaum tinha ainda experiência anterior no CNPq e na Organização Pan-Americana da Saúde (Opas). De 2003 a 2005, o professor presidiu a Abrasco, cargo que deixou para assumir a Secretaria de Ciência, Tecnologia e Insumos Estratégicos do Ministério da Saúde.

Esse período correspondeuà criação dos primeiros programas de mestrado profissional na área. O primeiro deles teve início em 2000 e foi oferecido pelo Instituto de Medicina Social da Uerj, seguindo-se em 2001 o programa do Instituto de Saúde Coletiva (ISC) da Ufba (Quadro 4). Diferentemente do que ocorreu em outras áreas do conhecimento, na saúde coletiva os primeiros cursos de mestrado profissional foram criados exatamente naqueles programas mais tradicionaise consolidados. Dessemodo, os mestrados profissionais foram elaborados segundo um patamar de qualidade que serviu de referência para novas propostas. Os primeiros programas exclusivamente de mestrado profissional - ou seja, um curso desvinculado de um programa acadêmico - foram o da Faculdade de Ciências Médicas da Santa Casa de São Paulo e o da Universidade de Pernambuco. 
Quadro 4 - Programas de pós-graduação iniciados entre 2000 e 2009 - Brasil

\begin{tabular}{|c|c|c|c|}
\hline $\begin{array}{c}\text { Instituição de } \\
\text { ensino superior }\end{array}$ & $\begin{array}{l}\text { Programa de } \\
\text { pós-graduação }\end{array}$ & $\begin{array}{l}\text { Ano início } \\
\text { mestrado }\end{array}$ & $\begin{array}{l}\text { Ano início } \\
\text { doutorado }\end{array}$ \\
\hline Uerj & Saúde Coletiva (MP) & 2000 & - \\
\hline ISC/Ufba & Saúde Coletiva (MP) & 2001 & - \\
\hline Ensp/Fiocruz & Saúde Pública (MP) & 2002 & - \\
\hline Ensp/Fiocruz & Saúde Pública e Meio Ambiente (MP) & $\begin{array}{c}2002 \\
\text { encerrado } 2009\end{array}$ & - \\
\hline Unisinos & Saúde Coletiva & 2002 & 2013 \\
\hline UEFS & Saúde Coletiva & 2003 & \\
\hline UFMT & Saúde Coletiva & 2003 & \\
\hline Unifor & Saúde Coletiva & 2003 & \\
\hline FCMSCSP & Saúde Coletiva (MP) & 2004 & \\
\hline IFF/Fiocruz & $\begin{array}{l}\text { Saúde da Criança e da Mulher } \\
\text { (MP) }\end{array}$ & 2004 & - \\
\hline Fesp/UPE & Vigilância sobre a Saúde (MP) & $\begin{array}{c}2004 \\
\text { descredenciado } 2010\end{array}$ & \\
\hline Unisantos & Saúde Coletiva & 2004 & 2013 \\
\hline CPqAM/Fiocruz & Saúde Pública (MP) & 2005 & - \\
\hline Unesa & Saúde da Família (MP) & 2005 & - \\
\hline Ensp/Fiocruz & Saúde Pública e Meio Ambiente & 2006 & 2006 \\
\hline Unifesp & Saúde Coletiva & 2006 & 2006 \\
\hline UFRGS & Epidemiologia (MP) & 2007 & - \\
\hline USP (FSP) & Vigilância em Saúde Pública (MP) & $\begin{array}{c}2007 \\
\text { descredenciado } 2010\end{array}$ & - \\
\hline Ufba (FM) & Saúde, Ambiente e Trabalho & 2007 & \\
\hline UFJF & Saúde Coletiva & 2007 & \\
\hline USP (FSP) & Nutrição em Saúde Pública & 2007 & 2007 \\
\hline UFMA & Saúde Coletiva & 2007 & 2009 \\
\hline UECE-UFC-Unifor & Saúde Coletiva & - & 2008 \\
\hline UEL & Gestão de Serviços de Saúde (MP) & 2008 & - \\
\hline Ufpel & $\begin{array}{c}\text { Saúde Pública Baseada em } \\
\text { Evidência (MP) }\end{array}$ & 2008 & - \\
\hline Ufac & Saúde Coletiva & 2008 & \\
\hline UFF & Saúde Coletiva & 2008 & \\
\hline Ensp/Fiocruz & Epidemiologia em Saúde Pública & 2008 & 2008 \\
\hline UEPB & Saúde Pública & 2009 & \\
\hline UFPE & Integrado em Saúde Coletiva & 2009 & \\
\hline
\end{tabular}


Progressivamente, foram criados novos cursos e programas de mestrado profissional, mas até o fim da década de 2000 não havia nenhuma instituição promotora que não fosse uma instituição de ensino superior ou um instituto de pesquisa - mostrando assim a dificuldade existente na saúde coletiva, assim como em outras áreas de avaliação, de ampliar o escopo da pós-graduação stricto sensu para além dos ambientes acadêmicos.

Em 2001, a Faculdade de Medicina da USP/Ribeirão Preto comunicou à Capes o encerramento de seu curso de doutorado, em razão de grave crise institucional pela qual vinha passando o Departamento de Medicina Social. Dada a política da universidade de não reposição das vagas decorrentes dos processos de aposentadoria e de alguns óbitos, 0 grupo de docentes se viu muito reduzido e sem condições de manter o curso que tinha sido o segundo criado na área.

Somente em 2011 o programa da USP em Ribeirão Preto voltaria a contar com o curso de doutorado. Tal fato merece um registro à parte, não apenas por esse ter sido um dos programas pioneiros, mas também porque o grupo de docentes que o tinha implementado contribuiu de maneira importante para a formulação teórica do campo e para a formação de residentes, mestres e doutores, que foram nucleadores de outros programas no país.

Nos primeiros dez anos de existência da saúde coletiva como área de avaliação, a hegemonia das representações da área médica e odontológica, que participavam no CTC como representantes da grandeárea da saúde, era fonte permanente de tensão entre as áreas de medicina I, II e III e odontologia em face da saúde coletiva, da enfermagem, da educação física e da farmácia. Os critérios relativos aos itens e indicadores da avaliação eram unificados para a grande área, assim como a formulação do Qualis-periódicos, atendendo aos interesses e características das áreas dominantes e desconhecendo as particularidades das demais.

O Qualis da grande área da saúde passou a ser construído mediante critérios comuns, que consideravam para o grupo de periódicos internacionais estar indexado em bases como Medline para a categoria internacional $C$, ter fator de impacto abaixo da mediana para a categoria internacional B e igual ou acima da mediana para a categoria internacional A. As demais categorias eram definidas em cada área, uma vez que tinham impacto pequeno ou nulo nos critérios de avaliação para os níveis de excelência (Caponi \& Rebelo, 2005).

A saúde coletiva acatou os critérios fixados para a grande área da saúde, mas decidiu promover três de seus periódicos à categoria internacional $A$, ainda que eles apresentassem fatordeimpactoinferioràmediana-caso daRevistadeSaúdePúblicaedaRevistaPanamericana de Salud Pública - ou não tivessem seu fator de impacto medido, como era o caso de Cadernos de Saúde Pública. Essa decisão deu margem a muitas discussões entre os representantes. A decisão da área visava a fortalecer os dois periódicos nacionais com indexação internacional e o periódico editado pela Opas como estratégia de atração de maior número de artigos, facultando aos periódicos a possibilidade de uma seleção mais rigorosa de artigos e maior competitividade. Essaestratégia semostrou correta na medida em quealavancou os periódicos 
nacionais, transformando-osemimportantes veículos paraa disseminação dos conhecimentos produzidos na área, tanto no país quanto no exterior.

A produção da área no triênio 2001-2003 foi de 1.876 artigos, correspondendo a 1,54 artigo por docente permanente. A classificação deliberada das duas principais revistas brasileiras e da revista da Opas como internacional A distorcia a distribuição dos artigos da área, colocando $48 \%$ da produção como internacional A e apenas 6,3\% como internacional $B$, além de 19,3\% como internacional $C$. Apesar disso, como o critério para o conceito muito bom na produção científica estava baseado na publicação de três artigos internacionais, sendo pelo menos um em periódicos classificados como internacional $A$ ou $B$, por docente permanente no triênio, o impacto sobre as notas dos programas não era grande, uma vez que dois dos periódicos seriam corretamente classificados como internacional B e o outro como internacional $C$. Ainda assim, havia um sentimento generalizado nas áreas médicas de que a área da saúde coletiva tentava, com essa decisão, aumentar artificialmente a nota atribuída a seus cursos.

$\mathrm{Na}$ avaliação trienal de 2004, correspondente ao triênio 2001-2003, pela primeira vez - desde a instituição das notas seis e sete - programas de saúde coletiva foram avaliados com a nota seis: o Programa em Epidemiologia da Universidade Federal de Pelotas (Ufpel); o Programa em Saúde Pública da Ensp/Fiocruz; e o Programa em Saúde Coletiva do ISC/ Ufba. Nenhum programa foi avaliado com a nota sete.

Esse ponto era objeto de discussão no Fórum de Coordenadores, havendo em seu interior duas correntes antagonistas: uma que defendia a permanência dos programas na nota cinco, argumentando que a área carecia de maior amadurecimento científico e que, portanto, não deveria ainda indicar programas como sendo de excelência; e outra que argumentava a favor da necessidade de se assumir a paridade entre a saúde coletiva e diversas outras das áreas de avaliação que apresentavam desenvolvimento semelhantee tinham programas com nota seis ou sete.

Nesse momento, a comissão de avaliação deliberou pela indicação de três programas para a nota seis, mas preferiu não indicar nenhum para a nota sete, acreditando que essa cautela era positiva para o campo porque estimularia os programas a buscarem novos patamares de excelência. Assim, mais de dez anos depois da individualização da saúde coletiva como área de avaliação e dos esforços da Abrasco para impulsionar e qualificar os programas de formação na área, três programas alcançaram a qualificação de excelência.

No fim do mandato do professor Moisés Goldbaum, havia em funcionamento, na área da saúde coletiva, 34 programas, dos quais 11 com cursos de mestrado e doutorado, 16 apenas com cursos de mestrado e sete mestrados profissionais. Em termos de expansão regional, não se registraram alterações comparativamente ao triênio anterior, existindo pelo menos um curso em cada estado nas regiões Sul e Sudeste, programas em três estados da região Nordeste e apenas um programa na região Centro-Oeste. Houve, entretanto, uma pequena 
extensão de programas para o interior dos estados de São Paulo, Rio Grande do Sul e Bahia. Da mesma forma, a composição dos programas continuava a ser ampla em sua maioria, com três programas de epidemiologia e um programa temático em saúde da criança e da mulher. Mesmo os mestrados profissionais aprovados na área mantinham o escopo amplo.

A posse do professor Jorge Guimarães na presidência da Capes em 2004 veio, por um lado, dar continuidade ao trabalho já iniciado por Abílio Baeta Neves aprimorando o processo de avaliação; e, por outro, enfatizar ainda mais a importância da pesquisa científica como nucleadora das atividades dos programas. Teve início um amplo processo de flexibilização da estrutura curricular dos programas, diminuindo-se a carga disciplinar e ampliando-se as atividades de pesquisa. Coerentemente com essa visão, a produção intelectual passou a ser o aspecto com maior poder de discriminação na nota.

O trabalho desenvolvido no Fórum de Coordenadores, ao longo dos anos, levou a maioria dos programas a solucionarem de maneira satisfatória os aspectos processuais relativos à composição do corpo docente, fluxo de alunos, alinhamento dos projetos às áreas de concentração e linhas de pesquisa, estrutura curricular e composição de bancas, entre outros. Assim, no âmbito da avaliação, foi ganhando espaço a produção intelectual, mesmo que o conjunto de quesitos e seus respectivos pesos não tenha sofrido alterações em relação ao triênio 1998-2000.

Para o período 2005-2007, foi indicado como representante de área o professor Aluísio Barros, formado em medicina pela Universidade Estadual de Campinas, onde também fez seu mestrado em estatística. Posteriormente, fez outro mestrado em estatística e o PhD em epidemiologia na London School of Hygiene and Tropical Medicine. Foi representante adjunto nesse mesmo triênio o professor Ricardo Ventura Santos, da Ensp. Ainda que o professor Aluísio não tivesse atéaquele momento atuado mais ativamente na vida associativa, participando de comissões ou cargos da diretoria, teve no desempenho de suas funções total sintonia com os valores defendidos pela Abrasco para a política de pós-graduação e para a política científica no país.

Dando prosseguimento ao processo de tornar os procedimentos avaliativos mais homogêneos entre as áreas e simplificar a avaliação, descartando itens desnecessários ou sem poder de discriminação na avaliação dos programas, foi proposta, em 2005, nova revisão das fichas de avaliação. A ficha que passou a ser usada contava agora com apenas cinco quesitos: a proposta do programa, o corpo docente, o corpo discente, a produção intelectual e um novo quesito relativo à inserção social do programa. A inclusão do quesito inserção social respondia à demanda expressa por algumas áreas de avaliação, entre as quais a de saúde coletiva, para que a avaliação levasse em conta a relevância social dos programas e não apenas seu nível de excelência acadêmica.

Além da reorganização dos sete anteriores para os cinco quesitos mencionados, houve um esforço de redução no número de itens de avaliação. Na grande área da saúde, os 36 itens 
das fichas de 1998 a 2004 foram inicialmente reduzidos para 21 em 2005, passando para vinte em 2006 e finalmente chegando a 18 em 2007. O CTC conseguiu discutir e propor 17 itens comuns a todas as áreas, deixando a cada uma delas a liberdade para acrescentar outros desde que os 17 itens comuns fossem considerados. Esse foi um grande esforço de confluência na avaliação, ainda que os critérios e os indicadores para avaliar cada aspecto continuassem a ser definidos em cada uma das áreas de avaliação ou em cada grande área. Tradicionalmente, a grande área da saúde e a grande área de engenharias procuravam estabelecer critérios e indicadores comuns, apesar da diversidade interna existente em ambas. Todo o processo de redefinição da ficha foi amplamente discutido no Fórum dos Coordenadores, contando com a ativa participação dos representantes de área, titular e adjunto, e com a participação de um ou mais membros da diretoria da Abrasco.

Nesse triênio, procurando responder à grande insatisfação dos pesquisadores da saúde coletiva, cuja produção intelectual era prioritária ou exclusivamente divulgada em livros e coletâneas, foi proposta a avaliação dessa produção mediante uma classificação das editoras, buscando valorizar editoras universitárias não comerciais, com tradição de publicação naárea, presença de conselho editorial e capacidade de distribuição. Na definição desses critérios, o grupo de trabalho estabelecido pelo Fórum de Coordenadores mostrou-se bastante ativo.

A adoção desse critério na avaliação da produção intelectual foi nova fonte de tensão entre a saúde coletiva e os representantes das áreas de medicina e odontologia, pois nelas não existia a tradição de divulgar resultados de pesquisa em livros ou coletâneas. Em medicina e odontologia, apenas conteúdos técnicos ou didáticos eram publicados em livros; assim, essas áreas faziam forte oposição a que os livros fossem considerados na produção intelectual dos programas, mesmo que ficassem restritos a livros de pesquisa.

A adoção de critérios mais rígidos de classificação da produção e a indução ao aumento da produção internacionalizada foram as principais marcas desse triênio. A Capes, como agência de fomento à pós-graduação, empenhou-se firmemente na internacionalização do conhecimento produzido nos programas brasileiros, buscando dar visibilidade aos grupos de pesquisadores nacionais e forçar a integração da ciência brasileira à ciência mundial.

A partir de 2007, a Capes considera o mestrado profissional como um programa separado do programa acadêmico, mesmo naquelas instituições em que os cursos foram inicialmente instituídos junto aos programas acadêmicos já existentes. Com isso, houve um aumento no número de programas sem aumento no número de cursos.

Os nove programas criados entre 2007 e 2009 representaram um aumento real, e seus programas temáticos ou disciplinares já eram maioria em relação aos de amplo espectro, apontando assim uma tendência que iria aumentar nos anos seguintes (Quadro 4). Essa tendência refletia, de um lado, a percepção da necessidade de se caminhar para formações mais especializadas, tendo em vista as demandas concretas de produção de conhecimentos e de formação profissional; de outro, a possibilidade de se poder contar em futuro próximo 
com a clientela oriunda dos cursos de graduação em saúde coletiva, que começam a ser implantados no Brasil em 2008, tornando menos necessária a oferta de uma formação ampla nos programas de pós-graduação.

Assim, no fim de 2007, a área contava com 39 programas, dos quais 31 eram acadêmicose oito eram profissionais. Entre esses 31 programas acadêmicos, 14 tinham cursos de mestrado e doutorado e 17 apenas cursos de mestrado. Os programas estavam presentes em todos os estados das regiões Sul e Sudeste, com alguma interiorização nos estados de São Paulo e Rio Grande do Sul; e em quatro estados da região Nordeste, com um programa no interior da Bahia. Havia apenas um programa na região Centro-Oeste, no estado do Mato Grosso.

A produção intelectual dos programas cresceu acentuadamente no triênio 2004-2006, aumentando em $91 \%$ o número de artigos publicados em relação ao triênio anterior. Foram registrados 3.588 artigos produzidos por alunos e docentes, dos quais $54,3 \%$ em periódicos classificados como internacional A e 27,4\% em periódicos classificados como internacional C. A proporção de artigos em periódicos internacional $B$ foi ainda menor do que no triênio anterior, atingindo apenas 1,3\%, evidenciando a necessidade de revisão do Qualis da área. Além de maior número total de artigos, houve crescimento no número de artigos por docente permanente, passando de 1,54 no triênio anterior para 1,93, dos quais 1,58 artigo por docente correspondia a artigos publicados em periódicos classificados como internacionais.

As tensões entre a área de saúde coletiva e a representação da grande área da saúde no CTC ficou mais uma vez evidenciada no transcurso da avaliação trienal, quando cerca de um terço das notas atribuídas pela comissão de área foi alterada na reunião do CTC, a despeito do trabalho extremamente criterioso e cuidadoso que havia sido feito. A representação de área e a comissão de avaliação, embora devendo acatar as decisões do conselho, fizeram uma manifestação formal ao diretor de avaliação contestando as alterações feitas pelo CTC e reiterando os critérios adotados pela área.

Na avaliação trienal de 2007, relativa ao triênio 2004-2006, a comissão de avaliação da área indicou um programa para a nota sete (epidemiologia da Ufpel) e dois para a nota seis (Ensp/Fiocruz e ISC/Ufba), mantendo os mesmos três programas de excelência do triênio anterior. No entanto, o CTC também atribuiu nota seis ao programa de epidemiologia da Universidade Federal do Rio Grande do Sul, ficando a área com quatro programas avaliados como de excelência.

O grande descontentamento entre os coordenadores de programas teve também repercussões no Fórum, com a instituição de algumas mudanças que o tornaram mais efetivo: a instituição de uma coordenação eleita pelos membros para melhor articular as reuniões semestrais; a criação de uma lista eletrônica permanente de discussão; a criação de um site específico, no qual existe uma biblioteca para divulgação de documentos de interesse produzidos por grupos de trabalho, atas das reuniões e documentos encaminhados pela representação da área. 
Ficou bem estabelecida, desde a última reunião de 2007, a vinculação do Fórum à Abrasco e sua independência em relação à representação de área na Capes. As agendas passaram a ser tarefa da coordenação do Fórum em comum acordo com o coordenador do programa anfitrião, sendo o representante e o adjunto convidados a participar das atividades. A primeira coordenação foi composta pelas professoras Maria Lúcia Bosi, do Programa de Mestrado da Universidade Federal do Ceará, e Maria Novaes, do Programa em Medicina Preventiva da USP.

A partir dessa nova configuração, as reuniões contaram sempre com temas previamente preparados por GTs especialmente constituídos para informar as discussões e torná-las mais produtivas. Tais mudanças demonstraram todo o seu potencial nos anos subsequentes, garantindo maior continuidade ao trabalho associativo a despeito da constante troca de componentes do Fórum, em razão das substituições dos coordenadores e vice-coordenadores dos programas, que ocorrem com periodicidade de dois a três anos, dependendo da instituição.

O Fórum de Coordenadores deixou de ser o local das lamúrias dos coordenadores e passou a se constituir efetivamente em um espaço de discussão, reflexão e proposição para a política de pós-graduação. Além disso, a nova configuração e o novo modus operandi facilitaram o compartilhamento de experiências de maneira mais eficiente, construindo uma rede de relações extremamente importante para dar suporte político institucional aos coordenadores de área na Capes.

Em 2008, a coordenação de área foi assumida pela professora Rita Barradas Barata, autora deste capítulo, formada em medicina pela Faculdade de Ciências Médicas da Santa Casa de São Paulo, com mestrado e doutorado em medicina preventiva, titulação obtida no Programa de Medicina Preventiva da USP. A autora participou ativamente da Abrasco desde sua criação, tendo inclusive sido coordenadora da comissão de epidemiologia em vários momentos e presidente da associação para o período 1997-2000. Pela segunda vez, desde sua criação, a área teve seu coordenador participando como membro eleito do CTC. Ricardo Ventura Santos permaneceu como coordenador adjunto, colaborando ativamente nos processos de seleção decursosnovoseno desenvolvimentoeimplementação da avaliação da produção em livros.

Durante o ano 2008 e parte considerável de 2009, o CTC esteve envolvido com a revisão do Qualis-periódicos. Estudos promovidos pela própria Diretoria de Avaliação, na época ocupada pelo professor Renato Janine Ribeiro, ${ }^{1}$ mostravam que o Qualis foi perdendo capacidade de discriminar adequadamente a produção dos programas, deixando de ser útil como ferramenta de avaliação.

Além da baixa capacidade de discriminação, não havia nenhuma comparabilidade entre as diferentes áreas, o que dificultava a análise pelo CTC, principalmente na atribuição

Em abril de 2015, o professor se tornou ministro da Educação do governo Dilma Rousseff. 
de notas seis e sete, que supostamente deveriam ser reservadas apenas aos programas com evidente internacionalização de sua produção.

A proposta elaborada pela Diretoria de Avaliação e aprovada pelo CTC implicava completa reformulação do Qualis, visando a solucionar os dois problemas anteriormente identificados. Em lugar da classificação anterior dos periódicos em internacional $A, B$ ou $C$; nacional $A, B$ ou $C$; e local $A, B$ ou $C$, foram propostos sete estratos, designados $A 1$, A2, B1, B2, B3, B4 e B5. Estabeleceram-se regras para forçar todas as áreas a construírem os estratos com poder de discriminação: 1) todos os periódicos da lista de cada área teriam que ser classificados - para isso foi instituído um estrato $C$, destinado aos periódicos não classificáveis e outros tipos de publicações que poderiam aparecer na lista indevidamente; 2) no máximo $50 \%$ dos artigos publicados poderiam ser classificados nos estratos superiores: A1, A2 e B1; 3) no máximo $25 \%$ dos artigos publicados poderiam ser classificados nos estratos $A 1$ e $A 2 ; 4)$ a proporção de artigos publicados no estrato $A 1$ teria que ser menor que a proporção de artigos publicados no estrato $A 2 ; 5$ ) o sistema de ponderação associado a cada estrato deveria guardar no mínimo 15 pontos de intervalo entre eles.

Essa proposta gerou enorme discussão tanto no âmbito do CTC quanto na comunidade acadêmica, pois havia uma quantidade enorme de problemas de concepção. Toda a lógica proposta penalizava periódicos que de alguma forma concentrassem parte da produção na área. Por exemplo, na área de saúde coletiva, os periódicos específicos ficavam em desvantagem em face de periódicos de áreas afins, nos quais parcela menor dos artigos eram publicados.

Após intensas discussões e numerosas simulações durante o ano 2008, a presidência da Capes decidiu modificar a proposta num aspecto fundamental:em vez de as porcentagens restritivas se aplicarem ao total de artigos, se aplicariam aos títulos, independentemente da concentração ou não da produção. Dessa forma, pôde ser superada a maioria das resistências, e o novo Qualis foi adotado.

Outra mudança que demandou grande trabalho ao CTC foi o desenvolvimento de uma proposta comum para avaliação de livros, coletâneas e capítulos. O CTC constituiu um grupo de trabalho para elaborar uma proposta de modo a normatizar o processo de avaliação destinado àquelas áreas do conhecimento para as quais a divulgação em livros fosse importante. A condução dos trabalhos coube aos coordenadores das áreas de educação, sociologia e saúde coletiva.

Em meados de 2009, foi possível aprovar a proposta em um seminário do qual participaram coordenadores de 26 áreas de avaliação. Posteriormente, a proposta também foi aprovada pelo CTC e incorporada aos instrumentos da avaliação trienal. A partir dessa deliberação, os livros, coletâneas e capítulos foram oficialmente reconhecidos como produção intelectual com a mesma importância dos artigos científicos nas áreas que optaram por incluí-los na avaliação dos programas, entre as quais a área da saúde coletiva. 
Passados quarenta anos da criação do primeiro programa de pós-graduação da área de saúde coletiva, estavam em funcionamento, em 2009, 45 programas, dos quais vinte com cursos de mestrado e doutorado, 14 apenas com curso de mestrado, dez mestrados profissionaise um doutoradoemassociação ampla dedois programascomcursos demestrado. A distribuição regional permanecia pouco alterada, a não ser pela criação do primeiro programa na região Norte e de um programa na Paraíba, estado da região Nordeste onde não havia nenhum programa da área.

A diretoria da Abrasco e o Fórum de Coordenadores organizaram uma nova pesquisa nos moldes daquela desenvolvida em 1995-1996, sob a coordenação da professora Cecilia Minayo, realizada nos anos 2008 e 2009, propiciando uma avaliação independente em relação à realizada pela Capes. Os pontos destacados dessa avaliação foram: melhor delimitação epistemológica docampo da saúde coletiva em torno da epidemiologia, dasciências sociais em saúdeedoplanejamentoegestãoem saúde;organizaçãosistêmicadosconteúdos disciplinares trabalhados; movimento crescente de interação interdisciplinar; ampliação dos objetos de estudo; maior interação entre pesquisadores, gestores e profissionais da saúde. Destaca-se também, segundo os autores, a progressiva consolidação de uma tradição científica e técnica. Todos esses avanços em relação à situação encontrada em 1997 refletiam a aprendizagem que a participação no Fórum propiciou aos coordenadores de todos os programas, favorecendo a troca entre programas consolidados e novos programas.

Apesar do aumento no número de programas, de docentes e de alunos titulados, a equipe responsável pela avaliação demonstrou preocupação com a estagnação do quadro docente em algumas instituições e até mesmo a redução observada em outras. Além do pequeno crescimento dos quadros docentes, os avaliadores assinalaram o processo de envelhecimento, uma vez que a idade média dos professores era de 51 anos. Outra mudança constatada em relação à avaliação feita em 1997-1998 dizia respeito à titulação dos docentes, que em sua imensa maioria havia sido obtida no próprio país, indicando assim a necessidade de se buscar experiência internacional por meio de programas de pós-doutorado.

Aconcentraçãogeográfica dos programas era menor do quea observadaem 1997-1998, tendo havido expansão nas regiões Sul e Nordeste, porém o déficit de programas nas regiões Norte e Centro-Oeste permanecia inalterado (Minayo, 2010). O estudo de egressos mostrou que, em sua maioria, eles atuavam como gestores ou técnicos no SUS ou como docentes em programas de graduação ou pós-graduação. Ou seja, havia no campo duas distintas clientelas, que possibilitavam à área uma definição cada vez mais clara entre programas com objetivos acadêmicos e programas com objetivos profissionais.

Na análise qualitativa e quantitativa da produção científica, chamou a atenção dos autores a redução significativa da proporção de artigos com autoria única e o aumento de pesquisas multicêntricas, em rede ou em parceria, além do aumento significativo no número de artigos publicados em revistas indexadas (Minayo, 2010). Passou-se de 591 artigos para 
2.126, com crescimento de 28\% entre a trienal 2001 (1998-2000) e a trienal 2004 (20012003) e de 46\% entre ela e a trienal 2007 (2004-2006) (Viacava, 2010).

A política de indução do aumento da produção qualificada se mostrou eficiente para o conjunto da produção brasileira e para a saúde coletiva em particular, conforme pode ser aquilatado pelo número de artigos de autores trabalhando em instituições brasileiras publicados em periódicos indexados na baseScopus eanalisados pelo SCImago (Gráficos 1 e2). Essesartigoscorrespondemnumericamentea $50 \%$ daproduçãoapresentadapelosprogramas em cada ano, uma vez que metade dos artigos produzidos na área são divulgados em periódicos de outras áreas da saúde, de áreas biológicas ou de humanidades e ciências sociais aplicadas.

Gráfico 1 - Artigos publicados na base Scopus. Brasil - 2001-2012

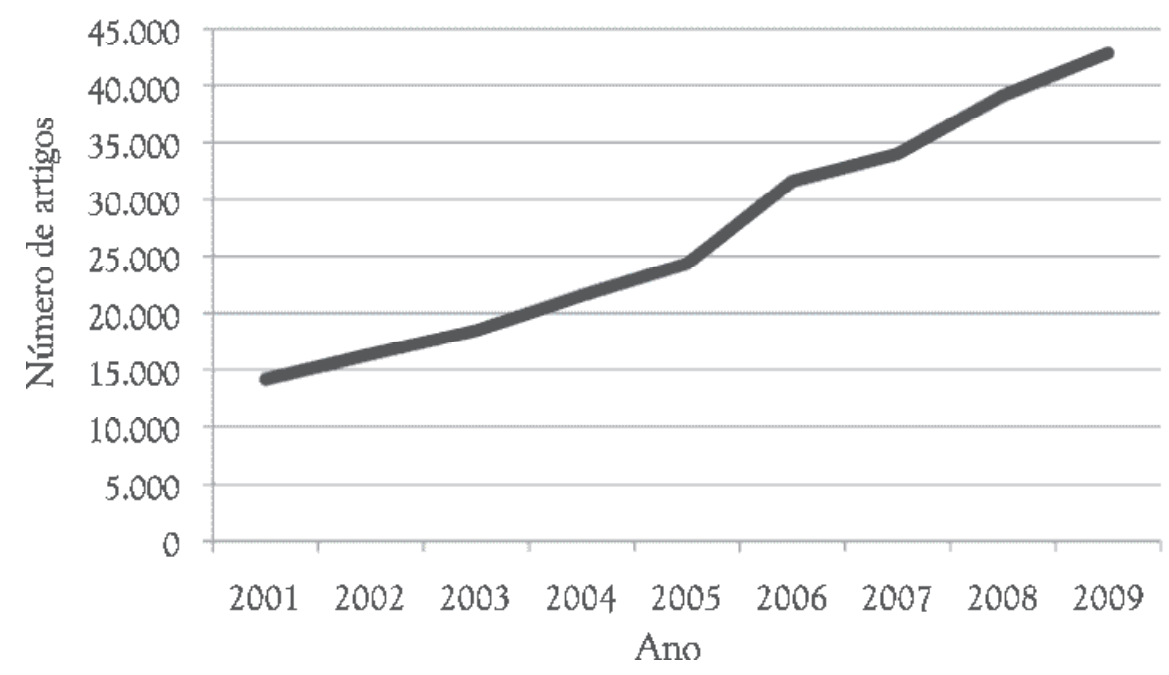

Finalmente, a pesquisa avaliativa analisou a importância e as características da cooperação internacional na área de saúde coletiva. A influência dos Estados Unidos e do Reino Unido reflete, por um lado, a importância desses centros no campo da saúde pública e, por outro, a própria história do desenvolvimento da pós-graduação no Brasil - que desde o princípio contou com o apoio financeiro de fundações americanas e britânicas, tais como Rockefeller, Ford, MacArthur, Fogarty e Wellcome Trust (Loyola, Correa \& Guimarães, 2010).

O número de bolsas para doutorado sanduíche ou pós-doutorado no exterior foi pequeno no período, e o número de projetos com cooperação - 383 no período 2004-2006 - era tanto maiorquantomaioranota do programa,emborahouvesseprogramascomnotatrêsapresentando até cinco projetos com cooperação internacional (Loyola, Correa \& Guimarães, 2010). A ampliação dessa cooperação internacional tornou-se um dos pontos destacados no período seguinte, sob a influência do programa Ciência sem Fronteiras. 
Gráfico 2 - Artigos sobre saúde coletiva publicados na base Scopus. Brasil - 2001-2012

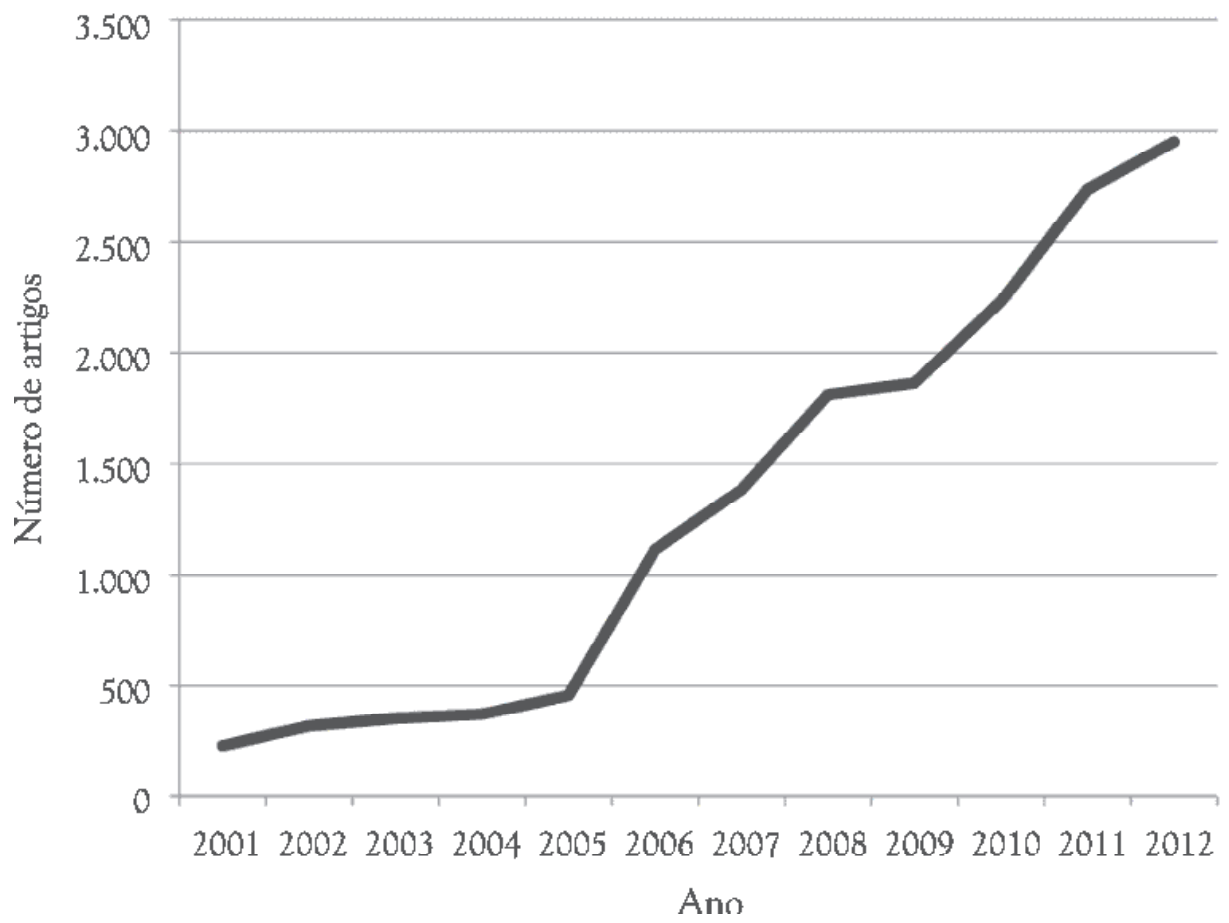

O Momento Atual: As duAs últimas AVAliações trienais (2010 E 2013)

Nesta etapa final da breve história que vimos traçando sobre a pós-graduação em saúde coletiva e sua relação intrínseca com a atuação da Abrasco, a coordenação de área continuou a ser desempenhada pela autora deste capítulo, tendo no segundo mandato como coordenador adjunto o professor Jorge Iriart, do Instituto de Saúde Coletiva da Ufba, e no último ano, como coordenadora adjunta para o mestrado profissional, a professora Eduarda Cesse, do Centro de Pesquisas Aggeu Magalhães, da Fiocruz.

A avaliação trienal 2010, relativa ao triênio 2007-2009, foi marcada por certa expectativa acerca do funcionamento do novo Qualis-periódico, da avaliação sistemática dos livros e do impacto que ambos poderiam vir a ter sobre as notas dos programas. Pela primeira vez, também, os programas de mestrado profissional foram avaliados por uma subcomissão dedicada exclusivamente a eles.

Foram avaliados cinquenta programas, dos quais 37 acadêmicos e 13 profissionais. De modo geral, a distribuição das notas se manteve semelhante à observada no triênio anterior. Entretanto, houve importante evolução no número de programas de excelência, que passaram de $10 \%$ para $16 \%$ do total de programas na área e de $30 \%$ para $40 \%$ daqueles com doutorado. Seis programas alcançaram a nota seis, dos quais três já haviam obtido seis 
na trienal anterior e três eram anteriormente avaliados com a nota cinco. Dois programas obtiveram a nota sete, um deles mantendo a nota anterior.

O crescimento relativo dos programas de excelência refletiu o acentuado crescimento da produção científica de qualidade; o aumento da massa crítica de pesquisadores; a maior disponibilidade de financiamentos para pesquisa; o trabalho constante da Abrasco no sentido de apoiar e fortalecer os programas e atuar ativamente no âmbito da política científica, ampliando os espaços para o campo da saúde coletiva.

A inclusão da avaliação de livros foi importante, ainda que menos de $6 \%$ da pontuação na produção da área tenha sido obtida por meio de livros, coletâneas e capítulos. Logo apóso término da trienal, o Fórum organizou um grupo de trabalho para estudar uma nova proposta para o Qualis-periódicos da área segundo as normas estabelecidas pelo CTC. O grupo de trabalho coordenado pelo professor Ivan França foi oficializado na Capes como a comissão de revisão do Qualis da área de saúde coletiva.

Após várias simulações e tentativas, a comissão responsável pela revisão propôs como estratégia para corrigir as distorções observadas, sem precisar artificialmente desclassificar periódicos de alto impacto mas de outras áreas do conhecimento, a separação inicial dos periódicos em dois grupos: um grupo de periódicos específicos da área de saúde coletiva e outro com periódicos de todas as demais áreas. Utilizando três medidas de impacto (índiceh, fator de impacto ou citações por documento enúmero médio de citações por artigo) e definindo os percentis de distribuição para o conjunto de periódicos existentes em cada base indexadora nos dois grupos, estabeleceram-se os pontos de corte correspondentes às duas listas e preencheram-se as cotas percentuais com periódicos dos dois grupos. Assim, foi possível tornar o Qualis mais adequado às características do campo sem penalizar a produção da área, publicada em veículos de outras áreas do conhecimento.

Considerando que a ciência atual é um empreendimento cada vez mais interdisciplinar, requerendo equipes com formações distintas, não há sentido em restringir a divulgação dos conhecimentos a periódicos específicos do campo da saúde coletiva. Assim, um periódico da área médica de alto impacto que publique, ainda que esporadicamente, artigos do campo, não tem por que ter sua classificação artificialmente rebaixada apenas por não ser da área. Do mesmo modo, um programa no qual docentes publiquem em periódicos de impacto não tem por que ser mal avaliado se esses periódicos não forem do campo da saúde coletiva.

A criação de novos cursos e programas naárea continuou demodoacelerado no período 2010-2013, com destaque para um crescimento expressivo dos mestrados profissionais apósa edição da portaria normativa n. 17, de dezembro de 2009, estabelecendo os parâmetros para essa modalidade de modo mais detalhado e completo do que as regulamentações anteriores (Quadro 5). 
Quadro 5 - Programas de pós-graduação iniciados entre 2010 e 2013 - Brasil

\begin{tabular}{|c|c|c|c|}
\hline $\begin{array}{l}\text { Instituição de ensino } \\
\text { superior }\end{array}$ & $\begin{array}{l}\text { Programa de } \\
\text { pós-graduação }\end{array}$ & $\begin{array}{l}\text { Ano início } \\
\text { mestrado }\end{array}$ & $\begin{array}{l}\text { Ano início } \\
\text { doutorado }\end{array}$ \\
\hline Ensp/Fiocruz & Epidemiologia em Saúde Pública (MP) & 2010 & - \\
\hline Imip & Avaliação em Saúde (MP) & 2010 & - \\
\hline UFG & Saúde Coletiva (MP) & 2010 & - \\
\hline UFRJ/Uerj/UFF/Ensp & Bioética e Saúde Coletiva & 2010 & 2010 \\
\hline CRH/SES-SP & Saúde Coletiva (MP) & 2011 & - \\
\hline UEFS & Saúde Coletiva (MP) & 2011 & - \\
\hline UFMG & $\begin{array}{c}\text { Promoção de Saúde e Prevenção da } \\
\text { Violência (MP) }\end{array}$ & 2011 & - \\
\hline UFSC & $\begin{array}{l}\text { Saúde Mental e Atenção Psicossocial } \\
\text { (MP) }\end{array}$ & 2011 & - \\
\hline Ufscar & Gestão da Clínica (MP) & 2011 & - \\
\hline UnB & Saúde Coletiva (MP) & 2011 & - \\
\hline UnB & Saúde Coletiva & 2011 & 2012 \\
\hline Renasf/Fiocruz & Saúde da Família (MP) & 2012 & - \\
\hline IEP/HSL & $\begin{array}{l}\text { Gestão de Tecnologia e Inovação em } \\
\text { Saúde (MP) }\end{array}$ & 2012 & - \\
\hline Unicamp & Saúde Coletiva, Políticas e Gestão (MP) & 2012 & - \\
\hline UFRGS & Saúde Coletiva & 2012 & \\
\hline FCMSCSP & Saúde Coletiva & 2012 & 2012 \\
\hline Furb & Saúde Coletiva (MP) & 2013 & - \\
\hline INC & Avaliação de Tecnologias em Saúde (MP) & 2013 & - \\
\hline UCPel & $\begin{array}{l}\text { Saúde da Mulher, da Criança e } \\
\text { Adolescente (MP) }\end{array}$ & 2013 & - \\
\hline UFMS & Saúde da Família (MP) & 2013 & - \\
\hline UFRN & $\begin{array}{c}\text { Gestão da Qualidade em Serviços de } \\
\text { Saúde (MP) }\end{array}$ & 2013 & - \\
\hline Uniceuma & $\begin{array}{l}\text { Gestão de Programas e Serviços de } \\
\text { Saúde (MP) }\end{array}$ & 2013 & - \\
\hline $\mathrm{USP} / \mathrm{RP}$ & Gestão de Organizações de Saúde (MP) & 2013 & - \\
\hline UFPA & $\begin{array}{l}\text { Saúde, Sociedade, Ambiente na } \\
\text { Amazônia }\end{array}$ & 2013 & \\
\hline Furg & Saúde Coletiva & 2013 & \\
\hline CPqRR/Fiocruz & Saúde Coletiva & 2013 & 2013 \\
\hline USP (FSP) & Epidemiologia & - & 2013 \\
\hline
\end{tabular}


Quadro 5 - Programas de pós-graduação iniciados entre 2010 e 2013 - Brasil (cont.)

\begin{tabular}{|l|c|c|c|}
\hline $\begin{array}{c}\text { Instituição de ensino } \\
\text { superior }\end{array}$ & $\begin{array}{c}\text { Programa de } \\
\text { pós-graduação }\end{array}$ & $\begin{array}{c}\text { Ano início } \\
\text { mestrado }\end{array}$ & $\begin{array}{c}\text { Ano início } \\
\text { doutorado }\end{array}$ \\
\hline USP (FSP) & Saúde Global e Sustentabilidade & - & 2013 \\
\hline FPS & $\begin{array}{c}\text { Multiprofissional para Fortalecimento } \\
\text { do SUS (MP) }\end{array}$ & 2011 & - \\
\hline UFVJM & Ensino na Saúde (MP) & 2011 & - \\
\hline
\end{tabular}

Paulatinamente, as grandesuniversidades brasileiras, principalmenteaquelas dosistema federal, foram abandonando sua posição restritiva à modalidade, ampliando a oferta de programas. Ao lado da mudança de posição entre as instituições públicas de ensino superior, também foi observado o aumento no número de propostas oriundas do setor privado e de outras instituições que não apenas as de ensino superior.

A partir do ano 2000, foi criado em média um programa de mestrado profissional por ano na área de saúde coletiva, até 2009. A partir de 2010 houve um aumento acelerado, tendo sido criados de quatro a cinco programas por ano. O mesmo fenômeno pode ser observado em outras áreas do conhecimento, aliado à expansão dessa modalidade para o conjunto do sistema de pós-graduação. Atualmente, apenas cinco das áreas de avaliação não têm nenhum programa profissional: antropologia e arqueologia, astronomia, filosofia, demografia e serviço social.

Nesses últimos quatro anos do período aqui analisado, houve crescimento de $60 \%$ no número de programas na área, sendo $22 \%$ para os acadêmicos e $190 \%$ para os profissionais. No fim de 2013, estavam credenciados na área 77 programas, dos quais 45 acadêmicos e 32 profissionais. Dos 45 programas acadêmicos, 29 são com mestrado e doutorado, 13 exclusivamente de mestrado e três exclusivamente de doutorado.

Os programas estão presentes em todos os estados da região Sul, nas capitais e em cidades do interior. Todos os estados da região Sudeste têm pelo menos um programa. Eles estão presentes em todas as capitais e em cidades do interior de São Paulo e Minas Gerais. Na região Centro-Oeste também há pelo menos um programa em cada estado e no Distrito Federal. Na região Nordeste, seis estados contam com programas, mas três estados, Piauí, Alagoas e Sergipe, não têm ainda nenhum na área de saúde coletiva. Na região Norte, existem programas apenas no Acre e no Pará, faltando em todos os demais estados.

Um ponto bastante sensível para a avaliação dos programas profissionais éa produção técnica, uma vez que nessa modalidade de formação o foco na produção científica deve ser menor do que para os programas acadêmicos. No entanto, não existem modelos nacionais ou internacionais para avaliar produção técnica adequados à pós-graduação. Na saúde coletiva, 
o Fórum de Coordenadores vem trabalhando na elaboração de uma proposta específica para a avaliação da produção técnica, levando em conta as especificidades dos programas acadêmicos e dos programas profissionais.

A avaliação trienal de 2013 mostrou na distribuição das notas o efeito do grande crescimento dos programas, havendo aumento importante daqueles com as notas três e quatro, redução dos que tinham nota cinco, aumento de um programa nota seis e aumento de dois programas nota sete. Em termos proporcionais, os programas de excelência mantiveram posição semelhante ao observado na trienal 2010, com 14\% em relação ao número total e $41 \%$ com relação aos programas com curso de doutorado.

O crescimento constante das publicações indexadas com circulação internacional foi observado paratodasasáreasquecompõemagrandeáreadasaúde,levandooscoordenadores a considerarem que a ênfase colocada na produção em momentos anteriores já cumpriu o papel indutor pretendido e que, portanto, no momento atual é necessário rever os critérios de avaliação e a ponderação entre os quesitos. Nos últimos anos, vem sendo discutida a necessidade de se contar com melhores informações sobre o desempenho dos alunos como medida da qualidade dos programas.

A pós-graduação em geral passa por uma nova mudança de ênfase, deslocando-se da questão centrada exclusiva ou prioritariamente na produção intelectual para maior peso no desempenho discente e na internacionalização dos programas. O programa Ciência sem Fronteiras, criado em 2011, representou um enorme incentivo à cooperação internacional. Outra tendência que vem se delineando é a necessidade de simplificar os procedimentos da avaliação com a redução do número de indicadores quantitativos utilizados, dando maior destaque à avaliação qualitativa global.

\section{Desafios e Perspectivas para o Desenvolvimento da Pós-Graduação em Saúde Coletiva}

Tendo em vista o estágio de desenvolvimento da área, as necessidades do país e as diretrizes do Plano Nacional de Pós-Graduação 2011-2020, os desafios que se apresentam para a área e para a Abrasco como a associação científica desse campo, dizem respeito a uma série de aspectos, dos quais destacaremos alguns.

É preciso expandir a pós-graduação em saúde coletiva para aquelas unidades da federação nas quais ainda não existem programas, garantindo a possibilidade desse tipo de formação em todos os estados brasileiros. A necessidade de profissionais qualificados para a formulação, a implementação e a avaliação das políticas de saúde é inegável. Entretanto, muitas das instituições de ensino e institutos de pesquisa da região Norte e de alguns estados do Nordeste não têm um número mínimo de docentes com formação em saúde coletiva, tornando muito difícil a instalação de programas. Duas estratégias poderiam ser 
implementadas visando a criar as condições apropriadas nesses estados: a utilização dos programas especiais como Programa de Apoio a Projetos Institucionais com a Participação de Recém-Doutores (Prodoc), Programa Nacional de Cooperação Acadêmica (Procad), Mestrado Interinstitucional (Minter) e Doutorado Interinstitucional (Dinter), pelos quais os programas de excelência da área poderiam auxiliar o desenvolvimento da capacidade local; e maior envolvimento da Abrasco, por meio do Fórum de Coordenadores, no processo de elaboração de novas propostas. No início de cada ano, a associação poderia promover um seminário para as instituições interessadas em oferecer novos cursos, de modo a auxiliá-las na preparação de propostas com possibilidade de aprovação.

Outro desafio importante está no aumento do número de doutores titulados pelos programas de saúde coletiva. O número de doutores é ainda relativamente pequeno para as necessidades do país, e os programas de excelência deveriam dedicar-se prioritariamente à sua formação, fazendo do mestrado acadêmico apenas uma etapa inicial e preparatória para o doutorado. O período do mestrado poderia ser dedicado à elaboração do projeto a ser desenvolvido no doutorado.

A nítida separação entre formação profissional, para a atuação no sistema de saúde, e a formação acadêmica, para a atuação na docência e na pesquisa, poderá favorecer a reconfiguração da pós-graduação no campo, de modo que o mestrado e o doutorado profissionais sejam reservados para a formação profissional qualificada. O doutorado acadêmico, com o mestrado apenas como uma etapa inicial dele, poderia estar totalmente dedicado à formação de pesquisadores.

Num primeiro momento, seria importante redefinir a vocação dos programas ora existentes, eliminando os chamados mestrados acadêmicos isolados e transformando-os em mestrados profissionais. Aárea poderia ter como diretriz, no caso dos programas acadêmicos, aprovarsomenteaquelescommestradoedoutorado ouaqueles exclusivamentededoutorado, eliminando os programas isolados de mestrado acadêmico.

Uma perspectiva que já vem se delineando nos últimos anos é a maior especialização ou particularização do escopo de abrangência dos programas. Com a criação dos cursos de graduação em saúde coletiva, os programas de pós-graduação acadêmicos deveriam buscar melhor especificação dos seus objetos de estudo, em razão das linhas de atuação de seu corpo docente, abandonando as propostas amplas e generalizantes. No âmbito dos programas profissionais, poderiam conviver programasamplos paraqualificaçãodesanitaristase programas especializadosem determinadasfunções dasaúdecoletiva, tendoemvistaa amplitudedocampo e a necessidade de se desenvolver a formação em um tempo relativamente curto.

Os programas deveriam priorizar as atividades formativas nos grupos de pesquisa, reduzind o a carga horária em disciplinas oferecidas em formato mais tradicional, e abandonar definitivamente os recortes disciplinares, substituindo-os por problemas e temáticas que requerem a abordagem inter ou transdisciplinar. Embora existam diferentes tradições 
de pesquisa no campo, cada vez mais os praticantes realizam trânsitos interdisciplinares de forma coerente com a complexidade dos problemas a serem estudados.

Outra tarefa pendente é o desenvolvimento de veículos e formatos adequados para o registro e a divulgação da produção técnica, de modo a que os produtos dos programas profissionais possam ser efetivamente incorporados pelo SUS na solução de problemas concretos. Há hoje, na política nacional de ciência e tecnologia, maior preocupação com a inovação e o desenvolvimento tecnológico. No entanto, a cultura científica brasileira ainda é marcadamenteacadêmica, como demonstram a própria dificuldade do mestrado profissional em se firmar como uma modalidade respeitada e a participação ainda incipiente de setores não acadêmicos na oferta dos programas.

A articulação da pós-graduação brasileira com as iniciativas de qualificação dos professores daeducaçãofundamental edoensino médio oferece uma oportunidadeà Abrasco de trabalhar a produção de materiais instrucionais e atividades de formação que possam levar para as escolas elementos importantes na formação de cidadania, com destaqueespecial para a reafirmação do direito à saúde e defesa do SUS, bem como de conteúdos especíicos de promoção da saúde. $O$ trabalho sobre novas gerações de brasileiros poderia vir a fortalecer temas que têm sido caros à associação desde a sua constituição.

Finalmente há necessidade de se repensar o modelo de avaliação e oferecer alternativas que permitam aprimorar o modelo atual, ajustando-o à realidade do número crescente de programas e às peculiaridades da área de saúde coletiva. A Abrasco foi pioneira na realização de avaliações independentes de seus programas, e seus associados sempre deram importantes contribuições para a elaboração de instrumentose indicadores. Esteéo momento de mais uma vez contribuir com essa expertise para se repensar o sistema de avaliação da pós-graduação brasileira.

\section{REFERÊNCIAS}

BARATA, R. B. Tendências do ensino da epidemiologia no Brasil. Revista Panamericana de Salud Pública, 2(5): 334-341, 1997.

BARATA, R. B. \& SANTOS, R. V. Ensino de pós-graduação em saúde coletiva: situação atual e desafios para o futuro. Revista Brasileira de Pós-Graduação, 10(19): 159-183, 2013.

COORDENAÇÃO DE APERFEIÇOAMENTO DE PESSOAL DE NÍVEL SUPERIOR (CAPES). 60 Anos - Revista Comemorativa, 2011.

CAPONI, S. \& REBELO, F. Sobre juízes e profissões: a avaliação de um campo disciplinar complexo. Physis: Revista de Saúde Coletiva, 15(1): 59-82, 2005.

FERREIRA, M. M. \& MOREIRA, R. L. Capes: 50 anos - depoimentos ao CPDOC/FGV. Brasília: Capes, FGV, 2002.

GOLDBAUM, M. \& BARATA, R. B. O feito por fazer. In: LIMA, N. T. \& SANTANA, J. P. (Orgs.). Saúde Coletiva como Compromisso: a trajetória da Abrasco. Rio de Janeiro: Editora Fiocruz, 2006. 
LOYOLA, M. A.; CORREA, M. C. D. V. \& GUIMARÃES, E. R. D. B. Cooperação internacional na área da saúde coletiva: propostas para um debate. Ciência \& Saúde Coletiva, 15(4): 2.007-2.020, 2010.

MacMAHON, B \& PUGH, T. F. Epidemiology, Principles and Methods. Boston: Little Brown and Co., 1970.

MINAYO, M. C. S. Pós-graduação em saúde coletiva: um projeto em construção. Ciência \& Saúde Coletiva, 2(1/2): 53-71, 1997.

MINAYO, M. C. S. Atuaçã̃o da Abrasco em relação ao ensino de pós-graduação na área de saúde coletiva. In: LIMA, N. T. \& SANTANA, J. P. (Orgs.). Saúde Coletiva como Compromisso: a trajetória da Abrasco. Rio de Janeiro: Editora Fiocruz, 2006.

MINAYO, M. C. S. Pós-graduação em saúde coletiva de 1997 a 2007: desafios, avanços e tendências. Ciência \& Saúde Coletiva, 15(4): 1.897-1.907, 2010.

NUNES, E.D.Tendências e perspectivas das pesquisas em ciências sociais em saúde na América Latina: uma visão geral. In: NUNES, E. D. (Org.). As Ciências Sociais em Saúde na América Latina. Brasília: Opas, 1985.

NUNES, E. D. Pós-graduação em saúde coletiva no Brasil: histórico e perspectivas. Physis: Revista de Saúde Coletiva, 15(1): 13-38, 2005.

NUNES, E. D.; FERRETO, L. F. \& BARROS, N. F. A pós-graduação em saúde coletiva no Brasil: trajetória. Ciência \& Saúde Coletiva, 15(4): 1.923-1.934, 2010.

SUSSER, M. Causal Thinking in Health Sciences. New York: Oxford University Press, 1973.

VIACAVA, F. Produção científica dos cursos de pós-graduação em saúde coletiva no período 1998-2006.

Ciência \& Saúde Coletiva, 15(4): 1.977-1.988, 2010. 